\title{
Epidemiology of non-fatal cerebrovascular stroke and transient ischemic attacks in Al Quseir, Egypt
}

\author{
Hamdy N El-Tallawy' \\ Wafaa MA Farghaly' \\ Ghaydaa A Shehata' \\ Nabil M Abdel-Hakeem ${ }^{2}$ \\ Tarek A Rageh' \\ Reda Badry' \\ Mahmoud R Kandil' \\ 'Department of Neurology and \\ Psychiatry, Faculty of Medicine, \\ Assiut University Hospital, \\ 2Department of Neurology, \\ Faculty of Medicine, \\ Al-Azhar University, \\ Assiut branch, Assuit, Egypt
}

This article was published in the following Dove Press journal:

Clinical Interventions in Aging

20 November 2013

Number of times this article has been viewed
Background and purpose: Stroke is a medical emergency that can cause permanent neurological damage, complications, and disability. We aim to determine the epidemiology of non-fatal cerebrovascular stroke (CVS) and transient ischemic attacks (TIAs) in Al Quseir City, Red Sea, Egypt.

Methods: The total population ( $n=33,285)$ was screened through a door to door study by three specialists of neurology and 15 female social workers (for demographic data collection). All suspected stroke patients were subjected to a full clinical examination, computerized tomography (CT) and/or magnetic resonance imaging (MRI) of their brain, blood sugar, lipogram, serum uric acid, complete blood cells, blood urea, and serum creatinine, as well as evaluated by Barthel Index and Scandinavian Stroke Scale. Carotid doppler, echocardiography, and thyroid functions were done for selected cases.

Results: CVS was recorded among 130 patients out of 19,848 subjects aged 20 years and more, yielding a total prevalence of 6.55/1,000 population. From June 1, 2010 to May 31, 2011, 36 patients were recorded to have stroke within 1-year, yielding an incidence rate of 1.81/1,000. Prevalence and incidence rates were higher among males than females, and both indices increased steadily with advancing age to reach the highest prevalence $(37.02 / 1,000)$ and incidence rate $(9.5 / 1,000)$ among aged persons 60 years and more.

Conclusion: The prevalence of non-fatal stroke in Al Quseir city $(6.55 / 1,000)$ was at the lower range of that recorded in developing countries $(5-10 / 1,000)$ and slightly higher than that recorded in industrialized countries (5/1,000 population). Ischemic stroke is the most common type of stroke. The prevalence of TIAs was $0.15 / 1,000$.

Keywords: stroke, TIAs, epidemiology, Egypt

\section{Introduction}

Stroke is the second most common cause of death and adult disability worldwide. ${ }^{1}$ An estimated 5.7 million people died as a result of stroke in 2005 and $87 \%$ of these deaths were in low-income and middle-income countries. ${ }^{2}$

Despite the advances of treatment of selected patients with stroke, the best approach is to prevent the occurrence of stroke. ${ }^{3}$ Determination of the prevalence of stroke is crucial for accurate health-care planning and delivery of appropriate interventions at various communities and institutional levels. ${ }^{4}$

The worldwide prevalence rate for cerebro-vascular diseases is between 500 and $700 / 100,000$ populations, ${ }^{5,6}$ and the crude prevalence is $1,169 / 100,000$.

The burden of cerebrovascular diseases in developing countries is rising sharply. ${ }^{7}$ The risk of stroke has increased $100 \%$ in low and middle income countries over the
Correspondence: Ghaydaa A Shehata Department of Neurology and Psychiatry, Assiut University Hospital, PO Box 71516, Assuit, Egypt

Tel +020882297075

Fax +02 0882333327

Email ghaydaa83@yahoo.com 
last decade and the developing world accounts for $85.5 \%$ of mortality due to all stroke deaths worldwide. ${ }^{8}$

The aim of this study is to estimate the prevalence and the incidence of non-fatal cerebrovascular stroke (CVS) and transient ischemic attacks (TIAs) in Al Quseir city, Red Sea Governorate, Egypt.

\section{Subjects and methods Study area}

Al Quseir city is the second largest city in Red Sea Governorate by population. Red Sea Governorate is the longest governorate in Egypt; it extends along 1,080 km and all its cities lie directly on the Red Sea. The length of Al Quseir city is $70 \mathrm{~km} .{ }^{9}$

\section{Study population}

The study sample consists of the entire population of Al Quseir city including all ages and both sexes $(7,497$ families; $n=33,285$ subjets) who had being living in this area for at least 6 months at the time of the study. All participants were interviewed directly, through door to door survey, by three neurologists accompanied by key persons in each locality of Al Quseir city to facilitate home visits. Fifteen female social workers accompanied the research team for demographic data collection. Subjects who were not present at home during the first visit were revisited again (capture recapture method) to decrease the number of drop out, and increase participation rate. Only 93 families $(0.12 \%$ of all households) refused to participate in this study.

\section{Stroke definition and case ascertainment}

The criteria for the diagnosis of stroke used was given by the World Health Organization (WHO) and is defined as: "rapidly developing clinical signs of focal (or global) disturbance of cerebral function lasting more than 24 hours (unless interrupted by surgery or death) with no apparent cause other than a vascular origin". ${ }^{10}$ TIAs were defined as an acute loss of focal brain or monocular function with symptoms lasting less than 24 hours and which is thought to be caused by inadequate cerebral or ocular blood supply as a result of arterial thrombosis, low flow, or embolism associated with arterial, cardiac, or hematological disease. ${ }^{11}$

\section{Phases of the study}

The study in Al Quseir city extended from July 1, 2009 to Jan 31, 2012 through eight phases: ${ }^{12}$ 1) data collection on the study area; 2 ) preparation phase (standardized questionnaire ${ }^{12}$ and detailed sheets of studied major neurological disorders);
3) screening phase; 4) case ascertainment; 5) investigations; 6) classifications; 7) data entry; and 8) statistics and tabulation.

\section{Methods}

All households ( $n=33,285)$ were screened by three neurologists, using a specifically designed Arabic questionnaire (sensitivity and specificity of $93.2 \%$ and $96 \%$, respectively).

All suspected cases of stroke were subjected to full evaluation in Al Quseir hospital, where detailed history was taken using a specialized sheet prepared specifically for this study. Full general and neurological evaluation were done using Scandinavian Stroke Scale (SSS) ${ }^{13}$ to evaluate severity of stroke, Barthel Index ${ }^{14}$ to measure the activities of daily living of the patients, and Mini Mental State Examination $(\mathrm{MMSE})^{15}$ to evaluate their cognitive functions. All patients were subjected to radiological investigations (computerized tomography [CT] scan and/or magnetic resonance imaging [MRI]) of the brain in Safaga or Luxor hospitals.

Special investigations were carried out for certain patients: neurophysiology and laboratory investigations according to their needs.

\section{Ethics}

The present study was approved by the ethical committee of Assiut University and the Ministry of Health to carry out this project in Al Quseir city. Signed informed written consent was obtained from all participants after a clear description of the objectives of this study to the members or responsible family member of the family.

\section{Statistical methods}

The statistical package for social sciences (SPSS) for Windows version 16 (SPSS Inc, IBM Corporation, Armonk, NY, USA) and Epicale 2000 were used for data analysis. The chi-squared test, independent samples $t$-test were used to analyze differences in proportions between group. The 95\% confidence interval (CI) for the prevalence was calculated using Excel (Microsoft Corporation, Redmond, WA, USA). A significance level of 0.05 was chosen.

\section{Results}

In the present study, the total population of $\mathrm{Al}$ Quseir city was screened $(33,285)$. The research team detected 130 cases of CVS out of 19,848 inhabitants aged 20 years and over, while a single case of stroke was identified in an 8 year old. Thus, the age specific ( $>20$ years old) prevalence of CVS was 6.55/1,000 (Table 1). Moreover, three cases of TIA were 
Table I Age and sex specific prevalence and incidence of CVS/I,000 population

\begin{tabular}{|c|c|c|c|c|c|c|}
\hline & Cases & Prevalence/I,000 & $\begin{array}{l}95 \% \text { confidence } \\
\text { interval }\end{array}$ & Cases & Incidence/I,000 & $\begin{array}{l}95 \% \text { confidence } \\
\text { interval }\end{array}$ \\
\hline Total & & & & & & \\
\hline $\begin{array}{l}\text { (population aged } 20 \text { years } \\
\text { or more }=19,848 \text { ) }\end{array}$ & 130 & 6.55 & $5.43-7.67$ & 36 & 1.81 & $|.22-2.4|$ \\
\hline Males $(n=9,9 \mid 6)$ & 85 & 8.6 & $6.76-10.05$ & 21 & 2.12 & $1.21-3.02$ \\
\hline Females $(n=9,932)$ & 48 & 4.8 & $3.47-6.19$ & 15 & 1.5 & $0.75-2.27$ \\
\hline $\begin{array}{l}\text { TIA (two males and one female; } \\
\text { population aged } 20 \text { years } \\
\text { or more }=19,848 \text { ) }\end{array}$ & 3 & 0.15 & $0.19-3.2$ & - & - & - \\
\hline
\end{tabular}

Notes: Three cases of TIA with a prevalence of 0.15/I,000; 119 cases of first stroke with a prevalence of 5.99/I,000/population; the incidence of first stroke was I.7/I,000 (34 cases); incidence was calculated from June I, 2010 to May 31 , $201 \mathrm{I}$.

Abbreviations: CVS, cerebrovascular stroke; TIA, transient ischemic attack.

recorded yielding a prevalence rate of $0.15 / 1,000$. During 1-year (June 1, 2010 to May 31, 2013) 36 subjects suffered stoke with an incidence rate of $1.81 / 1,000$ (Table 1). The prevalence and incidence of CVS were higher among male than female inhabitants (Table 1).

The lifetime prevalence and incidence rate increased steeply with advancing age (Table 2). Total lifetime prevalence and incidence of ischemic stroke was highest followed by intra-cerebral hemorrhage (Table 3 ).

\section{Discussion}

Assessment of the burden of stroke in our country is studied through two community based surveys ${ }^{12,16}$ using the door to door method. We chose this area because of its marked deficiency of preventive and prophylactic health measures. There are no neurologists in this region and it lacks of medical equipment (CT or MRI) and advanced laboratories. Moreover, the lack of stroke units and intensive care units, absence of specific protocols for early detection, and the prevalence and incidence of both morbidity and mortality rates of stroke in this area far from what is appreciated in well-equipped health centers.

In this study, the prevalence of stroke $(6.55 / 1,000)$, lies at the lower range of what is reported in developing countries (5-10 per 1,000 population), ${ }^{17}$ and slightly higher than that reported in industrialized countries ( 5 per 1,000 population). ${ }^{18}$
The prevalence of stroke in this study is higher than two epidemiological studies carried out in Egypt (5.6/1,000 in Al Kharga district ${ }^{19}$ and 5.08/1,000 in $\mathrm{Sohag}^{20}$ ). On the other hand, a lower prevalence of stroke was recorded in an earlier study from Saudi Arabia $(1.8 / 1,000)^{21}$ and a higher prevalence was recorded in Havana city, Cuba $(7.8 / 1,000) .{ }^{22}$ These differences in prevalence, even within the same country, might be explained by variation in genetic predisposition, dietary habits (mainly sea food in this area), differences of selection criteria, age of the population and differing adopted methodological assessments. In 2012, Zhang et al referred to some areas as having higher stroke prevalence than others, such as in the southeastern United States "stroke belts". ${ }^{23}$ Moreover, Tran and his colleague ${ }^{7}$ reported that the Middle East and North Africa region faces a double burden of the disease due to decreasing rates of communicable diseases and increasing rates of non-communicable diseases.

The incidence of stroke in the global population is approximately 2/1,000 per year. ${ }^{3}$ In Europe, the Monica Project showed that the annual incidence rates of stroke were between 1/1,000 (Friuli, Italy) and 2.9/1,000 (Kuopio, Finland), while in Qatar it was $1.24 / 1,000 .{ }^{24}$ The incidence rate recorded in $\mathrm{Al}$ Quseir city $(1.8 / 1,000)$ is lower than that record in Al Kharga district Egypt $(2.5 / 1,000)^{19}$ and in France $(2.4 / 1,000){ }^{25}$ From the prospective point of view, the incidence rate of stroke in this study is expected to be higher than the recorded data due to absence of health insurance systems

Table 2 Age specific prevalence and incidence rates of CVS/I,000 according to different age groups

\begin{tabular}{|c|c|c|c|c|c|c|}
\hline Age groups & Cases/population & Prevalence & $\begin{array}{l}95 \% \text { confidence } \\
\text { interval }\end{array}$ & Cases/population & Incidence/ I,000 & $\begin{array}{l}95 \% \text { confidence } \\
\text { interval }\end{array}$ \\
\hline $20-<40$ years & $3 / 11,664$ & 0.26 & $0.03-0.54$ & $0 / 11,664$ & 0 & - \\
\hline $40-<60$ years & $49 / 6,077$ & 8.06 & $5.8-10.3$ & $16 / 6,077$ & 2.63 & $1.34-3.92$ \\
\hline $60+$ years & $78 / 2,107$ & 37.02 & $28.96-45.51$ & $20 / 2,107$ & 9.5 & $5.35-13.63$ \\
\hline
\end{tabular}

Abbreviation: CVS, cerebrovascular stroke. 
Table 3 Age specific lifetime prevalence of CVS subtypes and TIA/I,000

\begin{tabular}{lllllll}
\hline $\begin{array}{l}\text { Subtypes } \\
\text { of CVS }\end{array}$ & $\begin{array}{l}\text { Cases (total } \\
\text { population =19,848) }\end{array}$ & $\begin{array}{l}\text { Prevalencel } \\
\mathbf{I , 0 0 0}\end{array}$ & $\begin{array}{l}\mathbf{9 5 \%} \text { confidence } \\
\text { interval }\end{array}$ & $\begin{array}{l}\text { Cases (total } \\
\text { population } \mathbf{2 0}=\mathbf{1 9 , 8 4 8})\end{array}$ & $\begin{array}{l}\text { Incidencel } \\
\mathbf{1 , 0 0 0}\end{array}$ & $\begin{array}{l}\mathbf{9 5 \%} \text { confidence } \\
\text { interval }\end{array}$ \\
\hline Infarction & 116 & 5.84 & $4.78-6.9$ & 34 & 1.7 & $1.13-2.29$ \\
Hemorrhage & 12 & 0.6 & $0.26-0.95$ & 1 & 0.05 & $0.05-0.15$ \\
SAH & 2 & 0.1 & $0.04-0.24$ & 1 & 0.05 & $0.05-0.15$ \\
TIA & 3 & 0.15 & $0.02-0.32$ & $\mathrm{I}$ & 0.05 & $0.05-0.15$ \\
\hline
\end{tabular}

Abbreviations: SAH, subarachnoid hemorrhage; TIA, transient ischemic attack; CVS, cerebrovascular stroke.

and lack of medical services required for early detection of risk factors and stroke prevention. From another point of view, the lower incidence rate recorded in $\mathrm{Al}$ Quseir could be attributed to loss of fatal cases of stroke due to lack of specified stroke units and well equipped intensive care units required for management of these cases. However, similar low incidence rates were recorded in previous studies, whether in Egypt (Sohag 1.8/1,000), ${ }^{16}$ or in other Arabic countries, such as Qater $(1.24 / 1,000),{ }^{24}$ Bahrain $(0.96 / 1,000),{ }^{26}$ Saudi Arabia $(0.4 / 1,000),{ }^{27}$ and Kuwait $(0.93 / 1,000) .{ }^{28}$

The prevalence and incidence rate were higher among males (8.6/1,000 and 2.12/1,000, respectively) than females (4.8/1,000 and 1.5/1,000, respectively). These results are in agreement with most previous studies ${ }^{19,29,30}$ that found a male preponderance for the occurrence of CVS. Also, a review of epidemiological studies of stroke found a male/female prevalence ratio of 1.41:1. ${ }^{29}$

Stroke is a disease of the elderly ${ }^{12,20,30}$ which was reported in this study: there was a steady increase in the prevalence and incidence of stroke with increasing age, especially at 60 years and greater $(37.02 / 1,000$ and 9.5/1,000, respectively). This is mostly attributed to the proportional increase of different risk factors of stroke with advancing age. On the other hand, some risk factors like hypertension, diabetes, and hyperlipidemia are usually discovered accidentally after the onset of stroke. These untreated risk factors have cumulative effects, pathological changes, and complications a few months or even years before the onset of stroke, with subsequent increased morbidly and mortality from the stroke among elderly patients.

The determination of the type of stroke is very important before planning the strategy for treatment that has a role regarding prognosis of stroke in the affected patients. This study confirmed the previous data in regards to the order of frequency of different types of stroke in which ischemic stroke $(89.2 \%)$ is the most frequent regarding prevalence $(5.08 / 1,000)$ and incidence $(1.7 / 1,000)$, in agreement with recorded epidemiological data from Pakistan ${ }^{31}$ and Italy ${ }^{23}$ which reported that $80 \%-85 \%$ and $83.2 \%$ of their patients had ischemic stroke, respectively.
The prevalence of TIAs in this study was $0.15 / 1,000$ and the incidence was $0.05 / 1,000$. This is lower than the reported crude overall annual incidence of TIA in Northern Portugal per 1,000 population $(0.67 ; 95 \%$ CI 0.45 to 1.04$) .{ }^{32}$ The lower prevalence rate of this study could be attributed to undervaluation of TIA cases. Thus, the lack of neurologists in Al Quseir, Egypt, can result in such cases being misdiagnosed as syncope attacks or any other medical conditions.

\section{Disclosure}

The authors report no conflicts of interest in this work.

\section{References}

1. Bonita R, Mendis S, Truelsen T, Bogousslavsky J, Toole J, Yatsu F. The global stroke initiative. Lancet Neurol. 2004;3(7):391-393.

2. Strong K, Mathers C, Bonita R. Preventing stroke: saving lives around the world. Lancet Neurol. 2007;6(2):182-187.

3. Sacco RL, Anand K, Lee HS, et al. Homocysteine and the risk of ischemic stroke in a triethnic cohort: the NOrthern MAnhattan Study. Stroke. 2004;35(10):2263-2269.

4. Raina SK, Razdan S, Pandita KK. Prevalence of stroke in Kashmiri migrant community. Neurology Asia. 2010;15(3):211-215.

5. Siekert RG, editor. Cerebrovascular Survey Report for Joint Counsil Subcommittee on Cerebrovascular Disease, National Institute of Neurological and Communicative Disorders and Stroke and National Heart and Lung Institute. Rochester; Whiting Press: 1980.

6. Sivenius J, Riekkinen P, Pyorala K, Heinonen O. Epidemiology of stroke in the Kuopio area, Finland. In: Abstracts of the Twelfth World Congress of Neurology, International Congress Series; Amsterdam. Abstract. 548;31.

7. Tran J, Mirzaei M, Anderson L, Leeder SR. The epidemiology of stroke in the Middle East and North Africa. J Neurol Sci. 2010; 295(1-2):38-40.

8. Feigin V, Carter K, Hackett M, et al; Auckland Regional Community Stroke Study Group. Ethnic disparities in incidence of stroke subtypes: Auckland Regional Community Stroke Study, 2002-2003. Lancet Neurol. 2006;5(2):130-139.

9. Saed MG, Aly SM, Karim A Masood, editors. Red Sea Governorate achievement index. 2012. [Arabic].

10. Aho K, Harmsen P, Hatano S, Marquardsen J, Smirnov VE, Strasser T. Cerebrovascular disease in the community: results of a WHO collaborative study. Bull World Health Organ. 1980;58(1):113-130.

11. Albers GW, Caplan LR, Easton JD, et al; TIA Working Group. Transient ischemic attack - proposal for a new definition. $N$ Engl J Med. 2002;347(21):1713-1716.

12. El Tallawy HN, Farghaly WM, Metwaly NA, et al. Door-to-door survey of major neurological disorders in Al Kharga District, New Valley, Egypt: methodological aspects. Neuroepidemiology. 2010;35(3):185-190.

13. Lindenstrøm ES, Christiansen LW, Simonsen E. Wernicke-Korsakoff syndrome at the Rikshospitalet in 1979-1988. A retrospective study. Ugeskr Laeger. 1991;153(40):2819-2822. Danish. 
14. Mahoney FI, Barthel DW. Functional evaluation: the Barthel index. Md State Med J. 1965;14:61-65.

15. Folstein MF, Folstein SE, McHugh PR. "Mini-mental state". A practical method for grading the cognitive state of patients for the clinician. J Psychiatr Res. 1975;12(3):189-198.

16. Kandil MR, Tohamy SA, Fattah MA, Ahmed HN, Farwiez HM. Prevalence of chorea, dystonia and athetosis in Assiut, Egypt: a clinical and epidemiological study. Neuroepidemiology. 1994;13(5):202-210.

17. Poungvarin N. Stroke in the developing world. Lancet. 1998; 352 Suppl 3:SIII19-SIII22.

18. Chong JY, Sacco RL. Epidemiology of stroke in young adults: race/ ethnic differences. J Thromb Thrombolysis. 2005;20(2):77-83.

19. El Tallawy HN, Farghaly WM, Rageh TA, et al. Epidemiology of major neurological disorders project in Al Kharga district, New Valley, Egypt. Neuroepidemiology. 2010;35(4):291-297.

20. Kandil MR AH, Farwez H. Incidence and prevalence of non-fatal cerebrovascular stroke and TIA in Upper Egypt (Sohag). Egypt J Neurol Psychiat Neurosurgry. 1996;33(1):37-44.

21. Al Rajeh S, Awada A, Niazi G, Larbi E. Stroke in a Saudi Arabian National Guard community. Analysis of 500 consecutive cases from a population-based hospital. Stroke. 1993;24(11):1635-1639.

22. de Jesús Llibre J, Valhuerdi A, Fernández O, et al. Prevalence of stroke and associated risk factors in older adults in Havana City and Matanzas Provinces, Cuba (10/66 population-based study). MEDICC Rev. 2010;12(3):20-26.

23. Zhang Y, Chapman AM, Plested M, Jackson D, Purroy F. The Incidence, Prevalence, and Mortality of Stroke in France, Germany, Italy, Spain, the UK, and the US: A Literature Review. Stroke Res Treat. 2012; 2012:436125.
24. Hamad A, Hamad A, Sokrab TE, Momeni S, Mesraoua B, Lingren A. Stroke in Qatar: a one-year, hospital-based study. J Stroke Cerebrovasc Dis. 2001;10(5):236-241.

25. Rothwell PM, Coull AJ, Silver LE, et al; Oxford Vascular Study. Population-based study of event-rate, incidence, case fatality, and mortality for all acute vascular events in all arterial territories (Oxford Vascular Study). Lancet. 2005;366(9499):1773-1783.

26. Al-Jishi A, Mohan P. Profile of stroke in Bahrain. Neurosciences. 2000;5(1):30-34.

27. El Zunni S, Ahmed M, Prakash PS, Hassan KM. Stroke: Incidence and pattern in Benghazi, Libya. Ann Saudi Med. 1995;15(4):367-369.

28. Abdul-Ghaffar NU, el-Sonbaty MR, el-Din Abdul-Baky MS, Marafie AA, al-Said AM. Stroke in Kuwait: a three-year prospective study. Neuroepidemiology. 1997;16(1):40-47.

29. Appelros P, Stegmayr B, Terént A. Sex differences in stroke epidemiology: a systematic review. Stroke. 2009;40(4):1082-1090.

30. Das SK, Banerjee TK, Biswas A, et al. A prospective community-based study of stroke in Kolkata, India. Stroke. 2007;38(3):906-910.

31. Khealani BA, Hameed B, Mapari UU. Stroke in Pakistan. J Pak Med Assoc. 2008;58(7):400-403.

32. Correia M, Silva MR, Magalhães R, Guimarães L, Silva MC. Transient ischemic attacks in rural and urban northern Portugal: incidence and short-term prognosis. Stroke. 2006;37(1):50-55.
Clinical Interventions in Aging

\section{Publish your work in this journal}

Clinical Interventions in Aging is an international, peer-reviewed journal focusing on evidence-based reports on the value or lack thereof of treatments intended to prevent or delay the onset of maladaptive correlates of aging in human beings. This journal is indexed on PubMed Central, MedLine, the American Chemical Society's 'Chemical Abstracts

\section{Dovepress}

Service' (CAS), Scopus and the Elsevier Bibliographic databases. The manuscript management system is completely online and includes a very quick and fair peer-review system, which is all easy to use. Visit http://www.dovepress.com/testimonials.php to read real quotes from published authors. 